\title{
Biosimilars in the management of neutropenia: focus on filgrastim
}

\author{
This article was published in the following Dove Press journal: \\ Biologics: Targets and Therapy \\ 18 February 2016 \\ Number of times this article has been viewed
}

\author{
Désirée Caselli ${ }^{1}$ \\ Simone Cesaro² \\ Maurizio Aricò' \\ 'Medical Department, Pediatric Unit, \\ Azienda Sanitaria Provinciale Ragusa, \\ Ragusa, ${ }^{2}$ Department of Pediatrics, \\ Pediatric Hematology Oncology, \\ Azienda Ospedaliera Universitaria \\ Integrata, Verona, Italy
}

\begin{abstract}
Advances in chemotherapy and surgery allows the majority of patients to survive cancer diseases. Yet, the price may be a proportion of patients dying of complications due to treatment-induced infectious complications, such as neutropenia. With the aim of decreasing morbidity and mortality related to infectious complications, recombinant human granulocyte colony-stimulating factor (G-CSF), filgrastim, and pegylated filgrastim have been used to reduce time and degree of neutropenia. A biosimilar is a copy of an approved original biologic medicine whose data protection has expired. The patent for filgrastim expired in Europe in 2006 and in the US in 2013. This review analyses the available evidence to be considered in order to design a strategy of use of G-CSF and its biosimilars. The clinical and safety outcomes of biosimilars are well within the range of historically reported data for originator filgrastim. This underscores the clinical effectiveness and safety of biosimilar filgrastim in daily clinical practice. Biosimilars can play an important role by offering the opportunity to reduce costs, thus contributing to the financial sustainability of treatment programs.
\end{abstract}

Keywords: neutropenia, filgrastim, biosimilars, G-CSF, fever, prophylaxis

\section{Introduction}

Recent advances in chemotherapy and surgery allows the majority of patients to survive cancer diseases. Yet, the price of intensified chemotherapy may be a proportion of patients dying of complications of major morbidities due to treatment-induced infectious complications. Indeed, cure may require neutropenia, which, although transient and reversible, may sometimes be as profound and prolonged as to cause episodes of persistent fever requiring hospitalization., ${ }^{1,2}$

Neutropenia may not only be more severe in patients undergoing induction therapy for acute leukemia, or in the preengraftment phase of hematopoietic stem cell transplantation, particularly allogeneic, but also in some patients receiving standard-dose chemotherapy for other neoplasms. With the aim of decreasing morbidity and mortality related to infectious complications, recombinant human granulocyte colony-stimulating factor (G-CSF), filgrastim, and pegylated filgrastim have been used to reduce time and degree of neutropenia.

\section{Definitions}

\section{Neutropenia}

The risk of infection rises as the neutrophil count falls below $500 \mu \mathrm{L}^{-1}$ and is most related to the number of circulating neutrophils. Although various definitions have 
been reported, the most common is the presence of absolute neutrophil count of less than $500 \mu \mathrm{L}^{-1}$, or expected to decrease to $<500 \mu \mathrm{L}^{-1}$ within the next 48 hours. ${ }^{3}$ Profound neutropenia is defined as an absolute neutrophil count $<100 \mu \mathrm{L}^{-1}$.

\section{Fever}

In a neutropenic patient fever is a single episode of temperature $>38.3^{\circ} \mathrm{C}\left(101.3^{\circ} \mathrm{F}\right)$ or a temperature $>38^{\circ} \mathrm{C}\left(100.4^{\circ} \mathrm{F}\right)$ sustained for more than 1 hour. ${ }^{3}$ However, infection in neutropenic and immunocompromised patients may develop in the absence of fever, particularly in elderly or patients treated with corticosteroids.

\section{Granulocyte colony stimulating factors}

They are biological growth factors that promote the proliferation, differentiation, and activation of neutrophils in the bone marrow. GCSF works by reducing the transition time from stem cell to mature neutrophil, resulting in a larger number of functional and mature circulating neutrophils. ${ }^{4}$

The most commonly used type of recombinant G-CSF is filgrastim.

\section{Strategy of use of G-CSF}

The risk of developing fever in patients treated with chemotherapy is the most important factor to determine the indication for prophylactic G-CSF. The risk is related to the intensity of chemotherapy, the presence and degree of injury to the gastrointestinal mucosa, the presence of underlying damage to the patient's hematopoietic stem cells, the concurrent use of radiation, and the overall clinical status of the patient (ie, age and comorbid conditions). ${ }^{4}$

The use of G-CSF after the administration of chemotherapy may be different:

- "Primary prophylaxis," when neutropenia is expected to occur following a course of chemotherapy, but the patient has never experienced it.

- "Secondary prophylaxis," when the patient had a neutropenic fever in a previous course of similar chemotherapy and is thus expected to do so again.

- "Supportive" in the attempt to shorten the duration of severe chemotherapy-induced neutropenia in patients without fever ("afebrile neutropenia").

Administration of G-CSF is generally not recommended for routine treatment in patients with established fever and neutropenia. $^{3}$

\section{Primary prophylaxis}

May be used to decrease neutropenic fever and days of hospitalization, but also to maintain dose-intense chemotherapy, if survival benefits may be achieved. The use of CSFs was suggested previously in those cases in which the incidence of the neutropenic fever after a given regimen was $40 \%{ }^{5}$ Recent guidelines ${ }^{3,6-9}$ suggest extending this use, inasmuch, they recommend primary prophylaxis when the anticipated incidence of neutropenic fever is in the range of $20 \%$ or higher with a given regimen, and no other equally safe and effective regimen not requiring CSF is available. This was based on randomized trials showing that primary prophylaxis was cost-effective when the risk of neutropenic fever with a specific regimen exceeded $20 \%{ }^{8,9}$

Evidence from multiple randomized trials and metaanalyses supports the benefit of primary prophylaxis in reducing the frequency of hospitalization for antibiotic therapy, documented infection, and the rates of neutropenic fever in adults. ${ }^{10-12}$ The impact on survival (both short-term and longterm), and the effect in children, are less clear. ${ }^{13-17}$

The continued use of primary G-CSF prophylaxis during all chemotherapy cycles is supported by a randomized trial in women receiving chemotherapy for breast cancer. The trial was closed prematurely after an interim analysis disclosing a higher rate of febrile neutropenia in the group receiving G-CSF during the first two cycles only (36\% vs 10\%). ${ }^{18}$

American Society of Clinical Oncology guidelines 2015 recommend primary prophylaxis with CSFs for selected situations, such as patients aged 65 and older with diffuse aggressive lymphoma treated with curative chemotherapy, especially in the presence of comorbidities, or patients receiving dose-dense chemotherapy regimens that are supported by convincing efficacy data. Yet, the secondary - rather than primary - prophylaxis is preferred in all other conditions. ${ }^{7}$ Concerns are reported about the possible increase of pulmonary toxicity induced by the association of G-CSFs in patients with Hodgkin lymphoma receiving bleomycin. Yet, specific data are not available; toxicity is not reported with the same association in other types of cancer. ${ }^{19}$ Some clinical conditions may enhance the risk of adverse outcome, thus alleviating the choice to associate G-CSF (Table 1).

Table I Risk factors for poor clinical outcomes of febrile neutropenia or infection

- Age more than 65 years

- Absolute neutrophil count $<0.1 / 10^{9} / \mathrm{L}$

- Neutropenia expected to last more than 10 days

- Invasive fungal infection

- All clinically documented infections (fungal infection, pneumonia, sepsis syndrome)

- Hospitalization at the time of fever 


\section{Secondary prophylaxis}

Secondary prophylaxis is the administration of a G-CSF after a cycle complicated by a neutropenic fever episode. A prior episode of fever during neutropenia is a risk factor for developing fever during neutropenia in later cycles, with recurrences in $50 \%-60 \%$ of patients. ${ }^{20}$ This practice reduces the risk of a neutropenic fever by approximately one-half. ${ }^{21}$ The target is to maintain chemotherapy doseintensity avoiding dose reduction; but a dose reduction may be the first therapeutic choice if the chemotherapy is not curative. ${ }^{5}$ No published regimen has ever shown improved disease-free or overall survival when secondary prophylaxis was instituted and the dose of chemotherapy maintained in any setting.

\section{Treatment of patients with neutropenia}

No role is established for G-CSFs in afebrile patients who developed severe neutropenia after chemotherapy. There is recommendation against their use, and also not to use G-CSFs routinely as an adjunct to antibiotics, except for patients who remain neutropenic and febrile after the initiation of antibiotics. ${ }^{7}$

\section{Side effects}

Local reactions have included bruising and erythema at the injection site.

The use of growth factors is associated with a risk of general side effects, among which are fatigue (11\%), generalized weakness (4\%), and unspecified pain (2\%). ${ }^{22} \mathrm{~A}$ common side effect is musculoskeletal and bone pain in $~ 22 \%$ of patients; transient hypotension has been reported, primarily associated with filgrastim intravenous administration. Chest pain was reported by $5 \%$ of patients receiving filgrastim following myelosuppressive chemotherapy. Transient increase in alkaline phosphatase and lactate dehydrogenase was reported in $28 \%-57 \%$ of patients. Acute respiratory distress syndrome, glomerulonephritis, alveolar hemorrhage and hemoptysis, capillary leak syndrome, leukocytosis cutaneous vasculitis, Sweet's syndrome (acute febrile neutrophilic dermatosis), and reactivation of pseudogout have been reported. ${ }^{23}$

Hematologic complications include acute arterial thrombosis, thought to be due to filgrastim-induced platelet aggregation; occasionally petechiae, thrombocytopenia, anemia, myelodysplasia and myeloid leukemia, and sickle cell crisis, splenic rupture and splenomegaly.

Dermatologic reactions associated with filgrastim are alopecia (18\%), generalized maculopapular rash $(6 \%)$, reversible exacerbations of acne, and Sweet's syndrome (acute febrile neutrophilic dermatosis). Filgrastim administration has also been associated with rare exacerbations of psoriasis and vasculitis.

Gastrointestinal involvement is quite frequent: diarrhea $(14 \%)$, mucositis $(12 \%)$, anorexia $(9 \%)$, constipation $(5 \%)$, stomatitis (5\%), and sore throat (4\%) have been reported. Respiratory symptoms include dyspnea (9\%), cough (6\%), and alveolar hemorrhage and hemoptysis.

Hypersensitivity-type reactions have been primarily associated with intravenous administration, with dermatologic (rash, urticaria, facial edema), respiratory (wheezing, dyspnea), or cardiovascular (hypotension, bradycardia) alterations. Anaphylaxis following a first dose of filgrastim has also been reported.

Rarely, renal and endocrine (such as reversible clinical hypothyroidism) adverse effects have occurred.

Metabolic changes have included reversible increases in uric acid concentrations in $28 \%-57 \%$ of patients. G-CSFinduced decreased bone mineral density was reported in a Washington University School of Medicine study in mice, ${ }^{24}$ as well as in children with severe chronic neutropenia receiving chronic treatment with filgrastim. ${ }^{23}$

Since several hematopoietic and nonhematopoietic cell types express myeloid growth factor receptors, there has been a concern that certain malignant cell lineages might respond to therapy with a granulocyte CSF, potentially worsening the underlying condition, or by triggering the development of malignancy in a susceptible individual. Because of this issue, the use of G-CSFs has been limited in patients undergoing induction therapy for acute myeloid leukemia. In a systematic review of 25 randomized trials of chemotherapy with or without G-CSF for a variety of neoplasms, ${ }^{25}$ although Acute myeloid leukemia/myelodysplastic syndrome was reported in significantly more patients treated with G-CSF, all-cause mortality was significantly lower in patients receiving chemotherapy with G-CSF, and greater reductions in mortality were observed in patients who received greater chemotherapy dose intensity. Thus, while the use of myeloid growth factors during chemotherapy might someway increase the risk of a therapyrelated myeloid neoplasm, the absolute magnitude of the risk is small, and the risk is probably outweighed by the benefits of using CSFs in this setting.

A special mention should be made about patients with severe congenital neutropenia who benefit from long-lasting replacement therapy with G-CSF. In these subjects, a special propensity to develop acute myeloid leukemia/myelodysplastic 
syndrome was reported, thus suggesting adapting the G-CSF schedule especially on long-lasting therapies. ${ }^{26,27}$

\section{Biosimilars in the treatment of neutropenia}

A biosimilar is a copy of an approved original biologic medicine whose data protection has expired. ${ }^{28}$ The patent for filgrastim expired in Europe in 2006 and in the US in 2013.

Since the manufacturing processes remain proprietary, biosimilars are manufactured using independently developed proprietary process. Thus, the new biosimilar drug is a complex molecule of biological origin, produced with different methods, not chemically identical to the originator. It must be assessed more rigorously than generics, and thus not surprisingly the regulatory requirements of the European Medicines Agency (EMA) for the approval of biosimilars are more demanding. ${ }^{29}$ Biosimilars have to prove efficacy and safety comparable to the original product. $^{30}$

On the other hand, biosimilars can play an important role by offering the opportunity to reduce costs, thus

Table 2 Approved G-CSF biosimilars

\begin{tabular}{|c|c|c|}
\hline Brand & Company & $\begin{array}{l}\text { Approval date, } \\
\text { note }\end{array}$ \\
\hline Filgrastim Ratiopharm & Ratiopharm & $\begin{array}{l}\text { September } 2008 \\
\text { but withdrawn } \\
\text { from the EU } \\
\text { market in July } \\
201 \text { I }\end{array}$ \\
\hline Ratiograstim & Ratiopharm & September 2008 \\
\hline TevaGrastim & Teva Pharma & September 2008 \\
\hline Biograstim & AbZ-Pharma GmbH & September 2008 \\
\hline Filgrastim Hexal & Hexal & February 2009 \\
\hline Zarzio & Sandoz & February 2009 \\
\hline Nivestim & Hospira & June 2010 \\
\hline Nivestim & Hospira Pty Ltd. & September 2010 \\
\hline Nivestim & Hospira NZ Ltd. & May 2012 \\
\hline $\begin{array}{l}\text { Filgrastim BS Injection } \\
\text { Syringe "Mochida" }\end{array}$ & Mochida/Fuji Pharma & November 2012 \\
\hline $\begin{array}{l}\text { Filgrastim BS Injection } \\
\text { Syringe "Nippon } \\
\text { Kayaku" }\end{array}$ & Nippon Kayaku/Teva & March 2013 \\
\hline Zarzio & Sandoz Pty Ltd. & May 2013 \\
\hline Grastofil & Apotex Europe BV & October 2013 \\
\hline Zarzio & Novartis NZ Ltd. & March 2014 \\
\hline $\begin{array}{l}\text { Filgrastim BS Injection } \\
\text { Syringe "Sandoz" }\end{array}$ & Sandoz & March 2014 \\
\hline Accofil & Accord Healthcare Ltd. & September 2014 \\
\hline Zarxio & Sandoz & March 2015 \\
\hline
\end{tabular}

Abbreviations: EU, European Union; G-CSF, granulocyte colony-stimulating factor. contributing to the financial sustainability of treatment programs.${ }^{30}$ Concerns were raised among hematologists on the use of biosimilar G-CSF in stem cell transplant until sufficient efficacy and safety data have been collected. ${ }^{31}$ In response, several centers have initiated studies in neutropenic patients, in autologous and allogeneic transplantation. The results have shown the benefit of biosimilars for this indication, supporting the extrapolation by EMA. ${ }^{32}$

Available evidence for equivalence between biosimilar G-CSF and the originator products comprises identical or very similar amino-acid sequence and production in Escherichia coli, ${ }^{32}$ results of trials in patients and volunteers, ${ }^{33}$ in neutropenic patients, ${ }^{34,35}$ during autologous ${ }^{36,37}$ as well as allogeneic stem cell mobilization in adults and children. ${ }^{38,39}$

EMA has approved several biosimilar versions, three of which are commercially available (Table 2). ${ }^{31}$ In March 2015 came the first approval for a biosimilar in the US - Zarxio, Novartis' copy of Amgen's white blood cell-boosting product Neupogen (filgrastim). The drug is used to reduce the risk of infection during chemotherapy. ${ }^{40}$

Prophylaxis or treatment of febrile neutropenia with biosimilars is cost-efficient. ${ }^{41}$ In the absence of convincing evidence that pegfilgrastim is pharmacotherapeutically superior to standard filgrastim, there is no cost-efficiency rationale to treat with that drug. ${ }^{40}$

The clinical and safety outcomes are well within the range of historically reported data for originator filgrastim, underscoring the clinical effectiveness and safety of biosimilar filgrastim in daily clinical practice. ${ }^{34-43}$

\section{Disclosure}

The authors report no conflicts of interest in this work.

\section{References}

1. Caggiano V, Weiss RV, Rickert TS, Linde-Zwirble WT. Incidence, cost, and mortality of neutropenia hospitalization associated with chemotherapy. Cancer. 2005;103:1916-1924.

2. Lyman GH, Michels SL, Reynolds MW, Barron R, Tomic KS, Yu J. Risk of mortality in patients with cancer who experience febrile neutropenia. Cancer. 2010;116:5555-5563.

3. Freifeld AG, Bow EJ, Sepkowitz KA, et al. Clinical practice guideline for the use of antimicrobial agents in neutropenic patients with cancer: 2010 update by the Infectious Diseases Society of America. Clin Infect Dis. 2011;52:e56-e93.

4. Raposo CG, Marin AP, Baron MG. Colony-stimulating factors: clinical evidence for treatment and prophylaxis of chemotherapy-induced febrile neutropenia. Clin Transl Oncol. 2006;8:729-734.

5. Ozer H, Armitage JO, Bennett CL, et al. 2000 update of recommendations for the use of hematopoietic colony-stimulating factors: evidence-based, clinical practice guidelines. American Society of Clinical Oncology Growth Factors Expert Panel. J Clin Oncol. 2000;18: $3558-3585$. 
6. Aapro MS, Bohlius J, Cameron DA, et al. 2010 update of EORTC guidelines for the use of granulocyte-colony stimulating factor to reduce the incidence of chemotherapy-induced febrile neutropenia in adult patients with lymphoproliferative disorders and solid tumours. Eur $J$ Cancer. 2011;47:8-32.

7. Smith TJ, Bohlke K, Lyman GH, et al. Recommendations for the use of WBC growth factors: American Society of Clinical Oncology Clinical Practice Guideline Update. J Clin Oncol. 2015;33:3199-3212.

8. National Comprehensive Cancer Network (NCCN). NCCN Clinical Practice Guidelines in Oncology. Available from: http://www.nccn. org/professionals/physician_gls/f_guidelines.asp. Accessed June, 2015.

9. Smith TJ, Khatcheressian J, Lyman GH, et al. 2006 update of recommendations for the use of white blood cell growth factors: an evidencebased clinical practice guideline. J Clin Oncol. 2006;24:3187-3205.

10. Kuderer NM, Dale DC, Crawford J, Lyman GH. Impact of primary prophylaxis with granulocyte colony-stimulating factor on febrile neutropenia and mortality in adult cancer patients receiving chemotherapy: a systematic review. J Clin Oncol. 2007;25:3158-3167.

11. Sung L, Nathan PC, Alibhai SM, Tomlinson GA, Beyene J. Metaanalysis: effect of prophylactic hematopoietic colony-stimulating factors on mortality and outcomes of infection. Ann Intern Med. 2007;147: 400-411.

12. Cooper KL, Madan J, Whyte S, Stevenson MD, Akehurst RL Granulocyte colony-stimulating factors for febrile neutropenia prophylaxis following chemotherapy: systematic review and meta-analysis. BMC Cancer. 2011;11:404.

13. Bohlius J, Herbst C, Reiser M, Schwarzer G, Engert A. Granulopoiesis-stimulating factors to prevent adverse effects in the treatment of malignant lymphoma. Cochrane Database Syst Rev. 2008;(4): CD003189.

14. Bennett CL, Djulbegovic B, Norris LB, Armitage JO. Colonystimulating factors for febrile neutropenia during cancer therapy. N Engl J Med. 2013;368:1131-1139.

15. Ladenstein R, Valteau-Couanet D, Brock P, et al. Randomized trial of prophylactic granulocyte colony-stimulating factor during rapid COJEC induction in pediatric patients with high-risk neuroblastoma: the European HR-NBL1/SIOPEN study. J Clin Oncol. 2010;28(21): 3516-3524.

16. Lyman GH, Dale DC, Culakova E, et al. The impact of the granulocyte colony-stimulating factor on chemotherapy dose intensity and cancer survival: a systematic review and meta-analysis of randomized controlled trials. Ann Oncol. 2013;24:2475-2484.

17. Pui CH, Boyett JM, Hughes WT, et al. Human granulocyte colonystimulating factor after induction chemotherapy in children with acute lymphoblastic leukemia. N Engl J Med. 1997;336:1781-1787.

18. Aarts MJ, Peters FP, Mandigers CM, et al. Primary granulocyte colony-stimulating factor prophylaxis during the first two cycles only or throughout all chemotherapy cycles in patients with breast cancer at risk for febrile neutropenia. J Clin Oncol. 2013;31:4290-4296.

19. Fosså SD, Kaye SB, Mead GM, et al. Filgrastim during combination chemotherapy of patients with poor-prognosis metastatic germ cell malignancy. European Organization for Research and Treatment of Cancer, Genito-Urinary Group, and the Medical Research Council Testicular Cancer Working Party, Cambridge, United Kingdom. J Clin Oncol. 1998;16:716-724.

20. Haim N, Shulman K, Goldberg H, Tsalic M. The safety of full-dose chemotherapy with secondary prophylactic granulocyte colony stimulating factor (G-CSF) following a prior cycle with febrile neutropenia. Med Oncol. 2005;22:229-232.

21. Crawford J, Ozer H, Stoller R, et al. Reduction by granulocyte colonystimulating factor of fever and neutropenia induced by chemotherapy in patients with small-cell lung cancer. $N$ Engl J Med. 1991;325: 164-170.

22. Hollingshead LM, Goa KL. Recombinant granulocyte colonystimulating factor (rG-CSF). A review of its pharmacological properties and prospective role in neutropenic conditions. Drugs. 1991;42: 300-330.
23. US National Library of Medicine. Available from: http://www.nlm. nih.gov/medlineplus/druginfo/meds/a692033.html. Accessed January, 2016.

24. Hirbe AC, Uluçkan O, Morgan EA, et al. Granulocyte colony-stimulating factor enhances bone tumor growth in mice in an osteoclast-dependent manner. Blood. 2007;109(8):3424-3431.

25. Lyman GH, Dale DC, Wolff DA, et al. Acute myeloid leukemia or myelodysplastic syndrome in randomized controlled clinical trials of cancer chemotherapy with granulocyte colony-stimulating factor: a systematic review. J Clin Oncol. 2010;28:2914-2924.

26. Donadieu J, Leblanc T, Bader Meunier B, et al; French Severe Chronic Neutropenia Study Group. Analysis of risk factors for myelodysplasias, leukemias and death from infection among patients with congenital neutropenia. Experience of the French Severe Chronic Neutropenia Study Group. Haematologica. 2005;90(1):45-53.

27. Beaupain B, Leblanc T, Reman O, et al; French SCN Registry. Is pegfilgrastim safe and effective in congenital neutropenia? An analysis of the French Severe Chronic Neutropenia registry. Pediatr Blood Cancer. 2009;53(6):1068-1073.

28. Abraham I, Tharmarajah S, MacDonald K. Clinical safety of biosimilar recombinant human granulocyte colony-stimulating factors. Expert Opin Drug Saf. 2013;12(2):235-246.

29. EMA. Guideline on Similar Biologic Medicinal Products. Available from: http://www.ema.europa.eu/docs/en_GB/document_library/ Scientific_guideline/2009/. Accessed June, 2015.

30. EMA. Concept Paper Revision of the Guideline on Similar Biological Medicinal Product. Available from: http://www.ema.europa.eu/docs/en GB/document_library/Scientific_guideline/2011/11/WC500117987. pdf. Accessed June, 2015.

31. Shaw BE, Confer DL, Hwang WY, Pamphilon DH, Pulsipher MA. Concerns about the use of biosimilar granulocyte colony-stimulating factors for the mobilization of stem cells in normal donors: position of the World Marrow Donor Association. Haematologica. 2011;96(7): 942-947.

32. Gascon P. Presently available biosimilars in hematology-oncology: G-CSF. Target Oncol. 2012;7(Suppl 1):S29-S34.

33. European Medicines Agency. Assessment Report for Ratiograstim. Nonproprietary Name: filgrastim (EMEA/H/C/825). Available from: http://www.ema.europa.eu/docs/en_GB/document_library/EPAR_Public_assessment_report/human/000825/WC500047793.pdf. Accessed June, 2015.

34. Gascon P, Aapro M, Ludwig H, et al. Treatment patterns and outcomes in the prophylaxis of chemotherapy-induced (febrile) neutropenia with biosimilar filgrastim (the MONITOR-GCSF study). Support Care Cancer. Epub 2015 Aug 27.

35. Blackwell K, Semiglazov V, Krasnozhon D, et al. Comparison of EP2006, a filgrastim biosimilar, to the reference: a phase III, randomized, double-blind clinical study in the prevention of severe neutropenia in patients with breast cancer receiving myelosuppressive chemotherapy. Ann Oncol. 2015;26(9):1948-1953.

36. Publicover A, Richardson DS, Davies A, et al. Use of a biosimilar granulocyte colony-stimulating factor for peripheral blood stem cell mobilization: an analysis of mobilization and engraftment. $\mathrm{Br} J$ Haematol. 2013;162(1):107-111.

37. Gardellini A, Gigli F, Babic A, et al. Filgrastim XM02 (Tevagrastim ${ }^{\circledR}$ ) after autologous stem cell transplantation compared to lenograstim: favourable cost-efficacy analysis. Ecancermedicalscience. 2013;7:327.

38. Ferro HH, Juni M, Bello R, Vidal A, Diez RA, Pavlovsky S. Utilization study of filgrastim (Neutromax) during autologous haematopoietic precursor transplantation for myeloma and lymphoma patients. Transfus Apher Sci. 2009;41(2):87-93.

39. Cesaro S, Tridello G, Prete A, et al. Biosimilar granulocyte-colonystimulating factor for mobilization of autologous peripheral blood stem cells in pediatric hematology-oncology patients. Transfusion. 2015;55(2):246-252.

40. Burki TK. First biosimilar drug approved in the USA. Lancet Oncol. 2015;16(4):e161. 
41. Aapro M, Abraham I, Cornes P. European G5 countries of various regimens of filgrastim, biosimilar filgrastim, and pegfilgrastim to reduce the incidence of chemotherapy-induced febrile neutropenia. J Oncol Pharm Practice. 2012;18(2):171-179.

42. Tesch H, UlshaferT, Vehling-Kaiser U, Ottillinger B, Bulenda D, Turner M. Prevention and treatment of chemotherapy-induced neutropenia with the biosimilar filgrastim: a non-interventional observational study of clinical practice patterns. Oncol Res Treat. 2015;38(4):146-152.
43. Brito M, Esteves S, Andé R, Isidoro M, Moreira A. Comparison of effectiveness of biosimilar filgrastim (Nivestimâ), reference Amgen filgrastim and pegfilgrastim in febrile neutropenia primary prevention in breast cancer patients treated with neo(adjuvant) TAC: a non-interventional cohort study. Support Care Cancer. 2016;24(2):597-603.

\section{Publish your work in this journal}

Biologics: Targets \& Therapy is an international, peer-reviewed journal focusing on the patho-physiological rationale for and clinical application of Biologic agents in the management of autoimmune diseases, cancers or other pathologies where a molecular target can be identified. This journal is indexed on PubMed Central, CAS, EMBase, Scopus

\section{Dovepress}

and the Elsevier Bibliographic databases. The manuscript management system is completely online and includes a very quick and fair peerreview system, which is all easy to use. Visit http://www.dovepress. com/testimonials.php to read real quotes from published authors. 